\title{
Efficient Determination of PML/RAR $\alpha$ Fusion Gene by the Electrochemical DNA Biosensor Based on Carbon Dots/Graphene Oxide Nanocomposites
}

\author{
Zi-Yang Zhang' \\ Lin-Xiao Huang' \\ Zhi-Wei Xu' \\ Peng Wang' \\ Yun Lei ${ }^{1,2}$ \\ Ai-Lin Liu (1D) ${ }^{1,2}$ \\ 'Department of Pharmaceutical Analysis, \\ The School of Pharmacy, Fujian Medical \\ University, Fuzhou, 350I22, People's \\ Republic of China; ${ }^{2}$ Higher Educational \\ Key Laboratory for Nano Biomedical \\ Technology of Fujian Province, The \\ School of Pharmacy, Fujian Medical \\ University, Fuzhou, 350I22, People's \\ Republic of China
}

Correspondence: Yun Lei; Ai-Lin Liu Department of Pharmaceutical Analysis, The School of Pharmacy, Fujian Medical University, Fuzhou, 350I22, People's Republic of China

Tel +8659l 22862016

Email lypiglet@I63.com; ailinliu@fjmu. edu.cn
Purpose: The PML/RAR $\alpha$ fusion gene as a leukemogenesis plays a significant role in clinical diagnosis of the early stage of acute promyelocytic leukemia (APL). Here, we present an electrochemical biosensor for PML/RAR $\alpha$ fusion gene detection using carbon dots functionalized graphene oxide $(\mathrm{CDs} / \mathrm{GO})$ nanocomposites modified glassy carbon electrode $(\mathrm{CDs} / \mathrm{GO} / \mathrm{GCE})$.

Materials and Methods: In this work, the $\mathrm{CDs} / \mathrm{GO}$ nanocomposites are produced through $\pi-\pi$ stacking interaction and could be prepared in large quantities by a facile and economical way. The $\mathrm{CDs} / \mathrm{GO}$ nanocomposites were decorated onto electrode surface to improve the electrochemical activity and as a bio-platform attracted the target deoxyribonucleic acid (DNA) probe simultaneously.

Results: The CDs/GO/GCE was fabricated successfully and exhibits high electrochemical activity, good biocompatibility, and strong bioaffinity toward the target DNA sequences, compared with only the pristine CDs on GCE or GO on GCE. The DNA biosensor displays excellent sensing performance for detecting the relevant pathogenic DNA of APL with a detection limit of $83 \mathrm{pM}(\mathrm{S} / \mathrm{N}=3)$.

Conclusion: According to the several experimental results, we believe that the simple and economical DNA biosensor has the potential to be an effective and powerful tool for detection of pathogenic genes in the clinical diagnosis.

Keywords: acute promyelocytic leukemia, pathogenic genes, electrochemical biosensor, exsitu method, carbon nanomaterials

\section{Introduction}

Acute promyelocytic leukemia (APL), M3 subtype of acute myelocytic leukemia (AML), is a genetic disease characterized by a balanced reciprocal translocation between chromosomes 15 and 17. ${ }^{1}$ Over 95\% of all AMLs are characterized by chromosome reciprocal translocation, $\mathrm{t}(15 ; 17)$ (q22; q12). It involves the promyelocytic leukemia $(\mathrm{PML})$ and retinoic acid receptor alpha $(\operatorname{RAR} \alpha)$, resulting in the expression of PML/RAR $\alpha$ fusion gene. The translocation event, which fuses the PML gene with RAR $\alpha$ gene, gives rise to the PML/RAR $\alpha$ fusion gene that is the major trigger of APL. ${ }^{2}$ Besides, the single gene rearrangement plays an important role in leukemogenesis through antagonizing retinoic acid signaling and the regulatory pathways mediated by APL. Therefore, effective identification of PML/ RARA fusion gene has been believed to be a key point on early diagnosis and prognostic monitoring of APL. ${ }^{3}$ Up to now the clinical diagnostic methods mainly 
include flow cytometry (FCM), real-time quantitative reverse transcription PCR (RT-PCR) and fluorescence in situ hybridization (FISH).$^{4-6}$ Nevertheless, unfavorable outcomes in clinical diagnosis of APL would happen due to the limited sensitivity, time-consuming pretreatment and complicated operational process. Accordingly, it is urgent to develop a novel analytical method which is simple, rapid and cost-effective enough for the clinical detection of PML/RAR $\alpha$ fusion gene.

In recent years, the electrochemical deoxyribonucleic acid (DNA) biosensor as a novel and powerful tool for nucleic acids sensing has attracted more and more attention, ${ }^{7}$ owing to several considerable advantages, such as high efficiency, low cost, excellent selectivity and high sensitivity. ${ }^{8-10}$ In the past decades, to achieve better selectivity and higher sensitivity, a large number of nanomaterials have been explored and have been widely applied in terms of designing the high-performance electrochemical biosensor, ${ }^{11-18}$ due to their excellent chemical, physical and biological properties. ${ }^{19}$

Among the candidate nanomaterials being utilized to modify electrode, graphene oxide (GO), one of the most important derivatives of graphene, exhibits fascinating properties including large surface area, ease of synthesis and good biocompatibility, ${ }^{20}$ and contains various oxygen functional groups providing binding sites for the covalent immobilization of DNA. ${ }^{21-23}$ To improve the high sheet resistance and poor electronic conductivity and enhance the electrochemical activity, various kinds of nanoparticles were used to functionalize GO, including metal oxides nanoparticles, ${ }^{24}$ metal nanoparticles ${ }^{25}$ and quantum dots (QDs). ${ }^{26}$ Numerous researches based on different GObased nanocomposites used for the development of DNA biosensors have been reported in recent years, ${ }^{27-29}$ which can impart special and advantageous properties to electrochemical biosensors. It follows that the exploration of appropriate GO-based hybrid nanomaterials is beneficial to the development of ideal electrochemical sensing platforms with excellent performance for bioapplication. Among various nanoparticles used for the GO-based nanomaterials, carbon dots (CDs) are known as low toxic, stable, abundant, easy-to-prepare and cheap. ${ }^{29-31}$ Besides, CDs have displayed the excellent electrical conductivity and charge transport mobility, ${ }^{32-34}$ demonstrating the great potential as the modifiers of GO-supported hybrid materials for electrode modification. Therefore, there are several research groups that have prepared GO or reduced graphene oxide (rGO)-CDs composites with improving catalytic performance for electrochemical detection of small biological molecules, toxic heavy metal ions and endocrine interferent in recent years. ${ }^{35-37}$ For example, Chen et al utilized $\mathrm{Pt}$ nanoparticles-carbon dots/ionic liquid functionalized graphene oxide (PtNPs-CDs/IL-GO) nanocomposites to detect $\mathrm{H}_{2} \mathrm{O}_{2}$, in which sheets of CDs/ IL-GO were decorated with PtNPs via the in-situ reduction of $\mathrm{H}_{2} \mathrm{PtCl}_{6}$ using chemical agent. ${ }^{38}$ Canevari et al reported an electrochemical biosensor based on reduced graphene oxide (rGO)-carbon nanoparticles hybrid for the detection of bisphenol A wherein carbon nanoparticles acted as a reducing agent of GO to obtain $\mathrm{rGO}^{39}$ The integration of $\mathrm{GO} / \mathrm{rGO}$ with electroactive nanoparticles facilitates electrochemical sensor with high sensitivity. However, the nanocomposites in these cases prepared by in-situ reduction methods could suffer from the uncontrollable size and morphology resulting in a wide size distribution. For the large-scale production of $\mathrm{CDs} / \mathrm{GO}$ nanocomposites with a narrow size distribution and easily adjustable size and shape, Li and co-workers reported an N-doped carbon dots-graphene oxide hybrid for simultaneous stripping determination of cadmium and lead ions, wherein composites were produced by the ex-situ assembly of CDs onto the GO surface. ${ }^{40}$ It is obvious that $\mathrm{CDs} / \mathrm{GO}$ nanocomposites made by ex-situ methods are superior in terms of cost, synthesis ease and stability, suggesting that the development of electrochemical sensor based on $\mathrm{CDs} / \mathrm{GO}$ nanocomposites via this inexpensive and simple approach offers practical advantages both in cost and popularization. Simultaneously, other than having the impressive electrochemical performances, the three-dimensional spherical nanostructure of CDs with the high surface area to volume ratios could allow immobilization of the larger number of the DNA probe ${ }^{41}$ and the abundant carboxyl groups could support the better stability of immobilization of DNA probe compared with other nanoparticles, ${ }^{42}$ which are crucial for good stability and high performance of DNA biosensor. Recently, the electrochemical DNA biosensor using CDs/GO nanocomposite are seldom reported. Besides, the affordable and economical CDs/GO-based DNA biosensor should not use the expensive instrument, which could be adapted to the clinical detection in the underdeveloped, rural and remote area.

For the mass-production of the modification materials of electrode, we present an all carbon-based $\mathrm{CDs} / \mathrm{GO}$ nanocomposites by a facile synthetic method for optimizing and enhancing the performance of the electrochemical DNA biosensor for PML/RAR $\alpha$ fusion gene detection. 
The stepwise fabrication procedure of the electrochemical DNA biosensor is shown in Figure 1. The roomy surface of GO as a platform for the immobilization of target DNA and the strong conductivity of CDs enhance the sensitivity of DNA biosensor. In addition, methylene blue (MB) as an electrochemical indicator ${ }^{43}$ was employed to design electrochemical DNA biosensor. ${ }^{44} \mathrm{CDs} / \mathrm{GO}$ nanocomposites accelerate electron transfers between $\mathrm{MB}$ and the electrode, and expand the surface of the working electrode to load greater mass of the capture probe DNA. Different pulse voltammetry (DPV) was employed to study the interaction of MB with DNA. The alteration of current signals originating from the interaction of $\mathrm{MB}$ with singlestrand DNA (ssDNA) and double-strand DNA (dsDNA) could be utilized to monitor the hybridization event. Besides, the specificity of the designed biosensor was carried out for distinguishing mismatch sequences from complementary sequences. Under optimal conditions, this
DNA biosensor with $\mathrm{CDs} / \mathrm{GO}$ nanocomposites provide a good linear range and the low limit of detection for $\mathrm{PML} / \mathrm{RAR} \alpha$ fusion gene sequence.

\section{Materials and Methods Materials and Reagents}

Tris (hydroxymethyl) methyl aminomethane (Tris), ethylenediaminetetraacetic acid disodium salt (EDTA-2Na), dehydrated alcohol, potassium chloride $(\mathrm{KCl})$, potassium ferricyanide $\left(\mathrm{K}_{3} \mathrm{Fe}(\mathrm{CN})_{6}\right)$, potassium hexacyanoferrate $\left(\mathrm{K}_{4}\right.$ $\left.\mathrm{Fe}(\mathrm{CN})_{6}\right)$, potassium dihydrogen phosphate $\left(\mathrm{KH}_{2} \mathrm{PO}_{4}\right)$, concentrated nitric acid $\left(\mathrm{HNO}_{3}\right)$, sodium hydroxide $(\mathrm{NaOH})$, sodium chloride $(\mathrm{NaCl})$, sodium dihydrogen phosphate dihydrate $\left(\mathrm{NaH}_{2} \mathrm{PO}_{4} \cdot 2 \mathrm{H}_{2} \mathrm{O}\right)$, di-sodium hydrogen phosphate dodecahydrate $\left(\mathrm{Na}_{2} \mathrm{HPO}_{4} \cdot 12 \mathrm{H}_{2} \mathrm{O}\right)$ and phosphoric acid $\left(\mathrm{H}_{3} \mathrm{PO}_{4}\right)$ were purchased from Sinopharm Chemical Reagent Co. Ltd. (Shanghai, China).

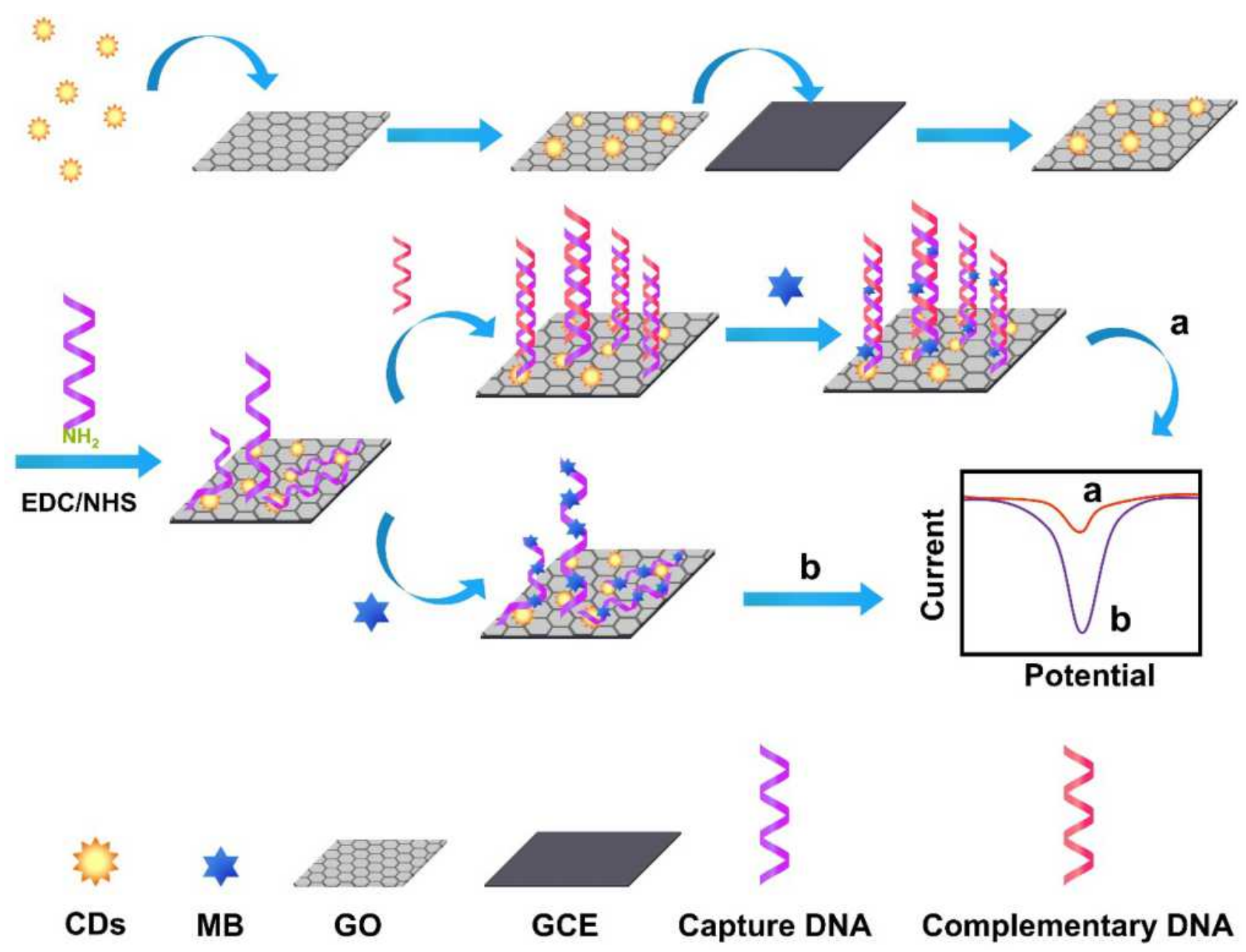

Figure I Schematic representation and measurement principle of the CDs/GO electrochemical biosensors.

Abbreviations: CDs, carbon dots; MB, methylene blue; GO, graphene oxide; GCE, glassy carbon electrode. 
1-(3-Dimethylaminopropyl)-3-ethylcarbodiimide hydrochloride (EDC), N-hydroxysulfo succinimide (NHS) and methylene blue (MB) were obtained from SigmaAldrich (Shanghai, China). Graphene oxide was purchased from Nanjing XFNANO Technology Co., Ltd (Nanjing, China). Carbon fibers were obtained from Shanghai Tansu Manufactory. All reagents were of analytical reagent grade and without further purification.

The synthetic oligonucleotides were purchased from Takara (Dalian, China), their base sequences were:

- Capture probe DNA (22-base sequence):

5'-NH 2 -GGTCTCAATGGCTGCCTCCCCG-3'

- Complementary target DNA (22-base sequence):

5'-CGGGGAGGCAGCCATTGAGACC-3'

- Single-base mismatch target DNA (22-base sequence):

5'-CGGGGAGGCACCCATTGAGACC-3'

- Partially-base mismatched target DNA (22-base sequence):

\section{5'-CGGGGAGGCAGAGGAACGCGTT-3'}

All oligonucleotides stock solutions $(100 \mu \mathrm{M})$ were prepared with Tris-EDTA (TE) buffer solution $(10 \mathrm{mM}$ Tris-HCl, $1.0 \mathrm{mM}$ EDTA, $\mathrm{pH}$ 8.0) and keep at -20 ${ }^{\circ} \mathrm{C}$. More dilute solutions of DNA were prepared with this stock solution. Besides, the phosphate buffered solutions (PBS, $\mathrm{pH}$ 7.4) were prepared by $\mathrm{Na}_{2} \mathrm{HPO}_{4}-\mathrm{NaH}_{2} \mathrm{PO}_{4}$ solution and $\mathrm{NaCl}$ solution and adjusted to $\mathrm{pH} 7.4$ using $\mathrm{NaOH}$ and $\mathrm{H}_{3} \mathrm{PO}_{4}$. The solutions were used high quality deionized water in all of the experiments.

\section{Apparatus}

Electrochemical studies were conducted using the CHI660D electrochemical workstation (Chenhua Instruments, China) and the Autolab PGSTAT302F electrochemical analyzer (Metrohm, Netherlands). A conventional three-electrode system was employed, covering a modified working electrode, an $\mathrm{Ag} / \mathrm{AgCl} / \mathrm{KCl}$ (saturated) reference electrode, and a platinum wire counter electrode. The CDs solution was purified by the 1000 Dalton $(1 \mathrm{kDa})$ dialysis bag (Spectrum, America) and was the ultrafiltered through the Millipore centrifugal filter devices with 3000 Dalton ( $3 \mathrm{kDa}$ ) molecular weight cutoff membranes (Millipore, America). Fluorescence spectra were obtained on the Cary Eclipse Fluorescence spectrophotometer (Agilent, America). UVvisible absorption (UV/Vis) spectra of CDs solution were recorded by a UV-2450 spectrometer (Shimadzu, Japan). Transmission electron microscopy (TEM) images were carried out using a Tecnai G2 F20 electron microscope (FEI, America) at an accelerating voltage of $200 \mathrm{kV}$. Scanning electron microscopy (SEM) images were taken by $\mathrm{S} 4800$ (HITACHI, Japan).

\section{Synthesis of Carbon Dots and CDs/GO Nanocomposites}

CDs was prepared by previously reported method. ${ }^{45}$ The detailed synthesis process of CDs is exhibited in the section of "Synthesis of carbon dots- Supplementary Information."

$\mathrm{CDs} / \mathrm{GO}$ nanocomposites were fabricated by sonication assembly method with GO nanosheets and CDs nanoparticles as precursors. The reaction procedure was as follows: The synthesized CDs powder was dissolved in deionized water at a concentration of $1 \mathrm{mg} / \mathrm{mL}$. Then, an appropriate amount of GO nanosheet was mixed to the above CDs solution in an ultrasonic bath for $30 \mathrm{~min}$. The different weight ratios $\left(\mathrm{W}_{\mathrm{CDs}}: \mathrm{W}_{\mathrm{GO}}\right)$ of 1:3, 1:5, 1:10, 1:30 and 1:50 of the CDs/GO nanocomposites were prepared by the above-mentioned method.

\section{Preparation of the DNA Biosensor with GO/CDs Nanocomposites}

Firstly, the bare GCE was polished carefully with $0.3 \mu \mathrm{m}$ and $0.05 \mu \mathrm{m} \mathrm{Al}_{2} \mathrm{O}_{3}$ powders followed by rinsing thoroughly with water. Then the electrode was washed in an ultrasonic bath sequentially with $\mathrm{HNO}_{3}$ solution ( $\left.\mathrm{v} / \mathrm{v}=1: 1\right)$, ethanol and doubly distilled water each for 3 min subsequently, and dried under nitrogen. Thereafter, the clean GCE was dropped with $8 \mu \mathrm{L} \mathrm{CDs} / \mathrm{GO}$ nanocomposites solution and allowed to dry in an oven at $60^{\circ} \mathrm{C}$ for 30 min. After washing with water, the $\mathrm{CDs} / \mathrm{GO} / \mathrm{GCE}$ was immersed into $100 \mu \mathrm{L}$ of phosphate buffer solution (10 $\mathrm{mM}, \mathrm{pH}$ 7.4) containing $20 \mathrm{mM} \mathrm{EDC}$ and NHS for 30 min. Afterwards, $8 \mu \mathrm{L}$ of $1 \mu \mathrm{M}$ capture probe DNA solution was pipetted onto the surface of $\mathrm{CDs} / \mathrm{GO} / \mathrm{GCE}$ and incubated for $2 \mathrm{~h}$ at room temperature to construct the capture probe DNA/CDs/GO/GCE electrode. Then, the capture probe DNA modified electrode was immersed in a solution of $10 \mathrm{mM}$ PBS (pH 7.4) containing $1 \mathrm{mM} \mathrm{MB}$ for $5 \mathrm{~min}$. The MB accumulated electrode was thoroughly rinsed with TE buffer solution and dried for further measurement. Replicate measurements were performed by renewing the surface and repeating the above assay preparation procedure.

\section{Experimental Measurement}

In the electrochemical experiment, cyclic voltammetry (CV) and differential pulse voltammetry (DPV) were carried 
out on a CHI660D electrochemical workstation. Electrochemical impedance spectroscopy (EIS) measurements were performed with Autolab PGSTAT302F electrochemical analyzer, and the value of open-circuit voltage (OCV) for EIS measurements is $0.23 \pm 0.01 \mathrm{~V}$. The electrochemical system consisted of the $\mathrm{Ag} / \mathrm{AgCl}$ (saturated $\mathrm{KCl}$ ) as the reference electrode, a platinum wire as an auxiliary electrode, and bare or modified GCE ( $3 \mathrm{~mm}$ in diameter) as the working electrode, respectively. Hybridization was performed by immersing capture probe DNA/CDs/GO/GCE into a certain concentration of the different target DNA solution at $35^{\circ} \mathrm{C}$ for $45 \mathrm{~min}$ and washed with TE buffer solution, then, dried in nitrogen to obtain the different hybridized double-strand DNA/CDs/GO/GCE. The DPV was recorded from 0.4 to $-0.6 \mathrm{~V}$ with amplitude of $0.05 \mathrm{~V}$, pulse width of $0.05 \mathrm{~s}$, and pulse period of $0.2 \mathrm{~s}$. Replicate measurements were recorded by renewing the surface and repeating the above assay preparation procedure.

\section{Results and Discussion \\ Characterization of CDs and CDs/GO Nanocomposites}

The morphology of CDs was characterized by transmission electron microscopy (TEM). As shown in Figure 2A, TEM image shows that the CDs are monodispersed and spherical. The size distribution histogram reveals that the particle sizes of CDs mostly range from 1.12 to $3.54 \mathrm{~nm}$ and the average diameters is $2.26 \pm 0.48 \mathrm{~nm}$ (Figure 2B). High-resolution TEM (HRTEM) images (Figure 2C) reveal the high crystallinity of the CDs in which the lattice spacing of $0.203 \mathrm{~nm}$ (the inset in Figure 2C) corresponds (102) crystal plane of
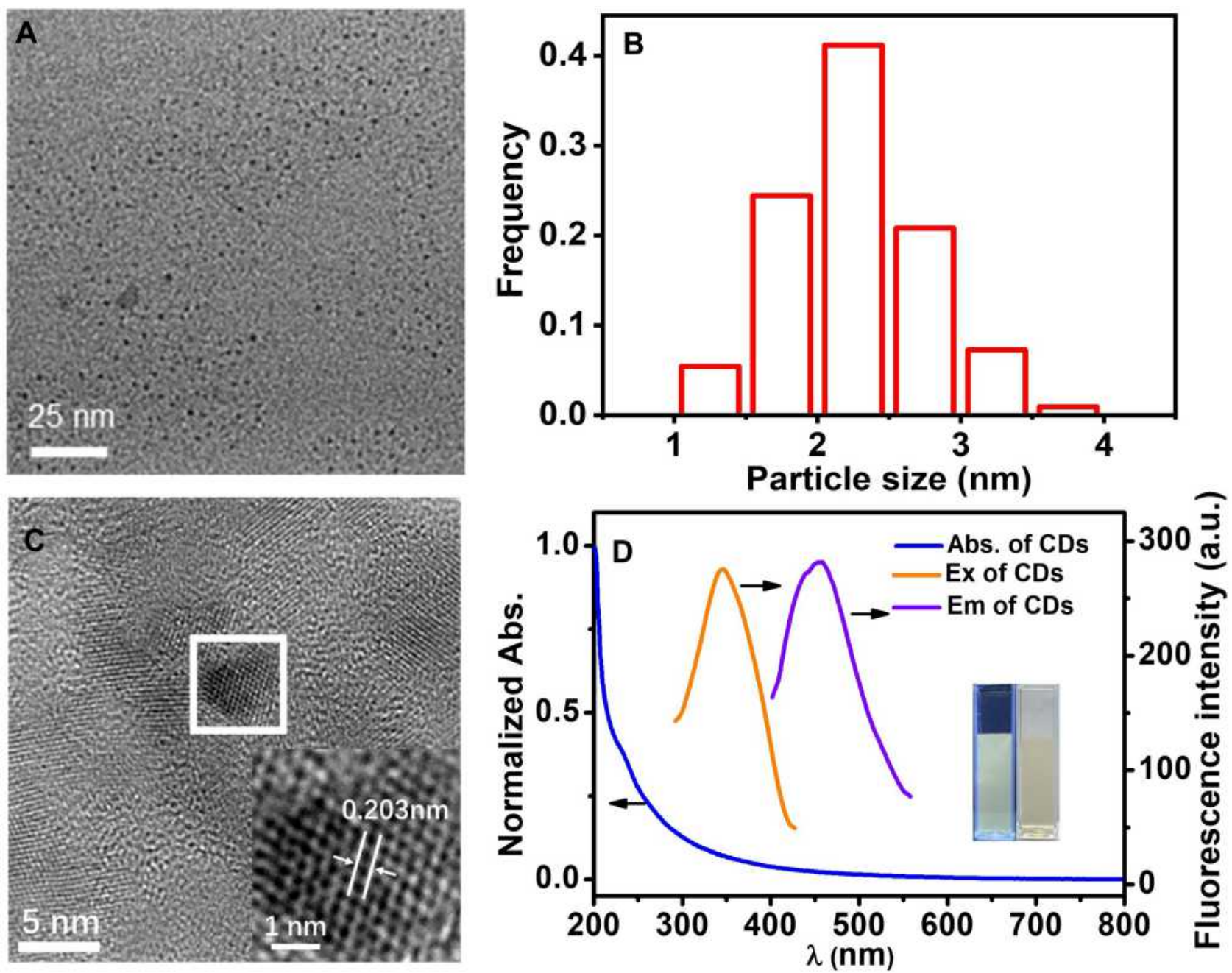

Figure 2 TEM (A) and HRTEM (C) images of the CDs; (B) Size distribution of the CDs; (D) Fluorescence spectra and UV/Vis absorption spectra of the CDs, inset in Figure 2C: HRTEM image of the single CDs, inset in Figure 2D: the photographs of the aqueous solution of the CDs (left) under UV light (365nm) and the CDs (right) under daylight lamp. 
graphitic $\left(\mathrm{sp}^{2}\right)$ carbon. The CDs solution shows a broad UVvis absorption with shoulder-type peak at $230 \mathrm{~nm}$ (Figure $2 \mathrm{D})$, which is the $\pi-\pi^{*}$ transition absorption of conjugated structure of CDs. Besides, the peak of the fluorescence excitation spectrum at $340 \mathrm{~nm}$ was symmetrical to the emission peak at $455 \mathrm{~nm}$ and the stokes shift was $90 \mathrm{~nm}$. Moreover, the inset in Figure 2D shows the aqueous solution of the CDs illuminated under the UV light (left, $365 \mathrm{~nm}$ ) and the white (right, daylight lamp). It is obvious that the aqueous solution of the CDs under the irradiation of the UV light at $365 \mathrm{~nm}$ has a light-yellow fluorescence bright enough to be easily seen with the naked eye.

CDs/GO nanocomposites were prepared by the ultrasonic blending method as described in the experimental section. To study the surface morphologies and the apparent characteristics of the different synthesized carbon nanomaterials, SEM and TEM were applied in detail. The SEM images (Figure 3A) reveal that GO obviously wrinkles that provides a large surface area, which facilitates loading the CDs material. Besides, Figure $3 \mathrm{~B}$ presents the representative
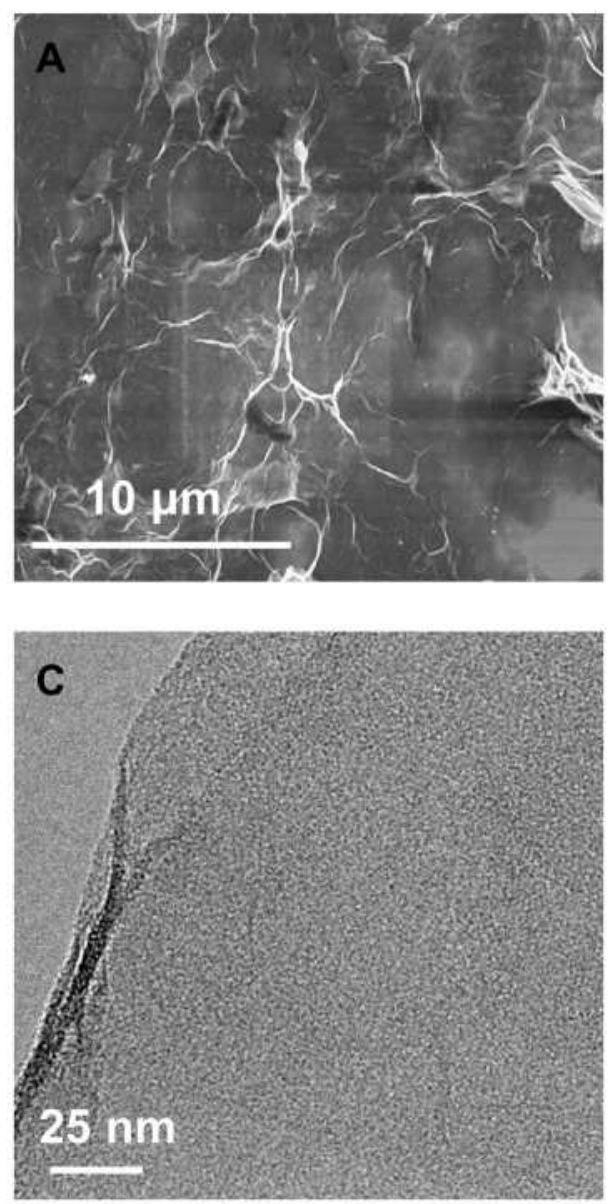

SEM image of CDs/GO nanocomposites. Upon mixed with CDs, the GO sheet becomes a uniformly close film, featuring as the obvious reduction of wrinkles. To further investigate the morphologies of GO and CDs/GO nanocomposites, both nanomaterials were imaged by TEM. As shown in Figure 3C, individual GO exhibits irregular two-dimension sheet-like structure with some crimple and fold effect. Compared with GO, the surface of $\mathrm{CDs} / \mathrm{GO}$ is significantly rougher and a mass of spherical CDs are found to evenly distribute throughout the surface of GO through $\pi-\pi$ stacking and electrostatic interactions (Figure 3D), owing to high surface area of GO and good dispersion provided by ultrasonic treatment.

\section{Electrochemical Behavior of Modified GCEs Based on CDs/GO Nanocomposites with Different Ratios}

Since the incorporation of nanomaterials will affect the physical and chemical properties of the GO-based composites,
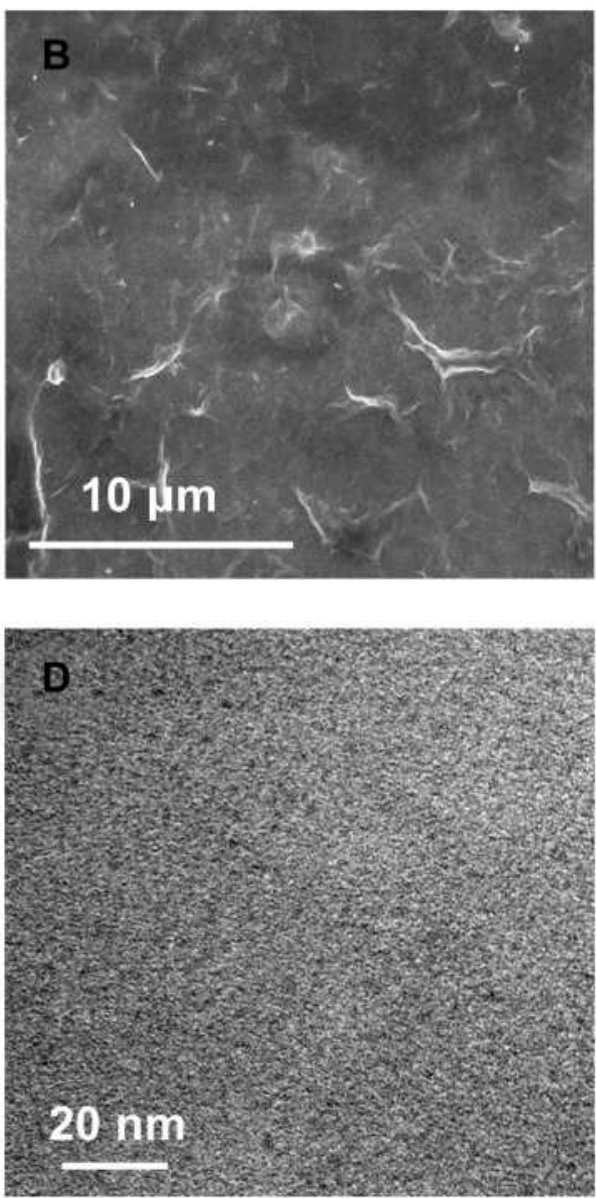

Figure 3 SEM images of the GO (A) and CDs/GO nanocomposites (B); TEM images of the GO (C) and CDs/GO nanocomposites (D). 
the optimization of the precursor's ratio is very crucial. In order to improve the electrochemical properties of $\mathrm{CDs} / \mathrm{GO}$ nanocomposites modified electrode, the different weight proportion of $\mathrm{CDs} / \mathrm{GO}$ nanocomposites should be examined. A typical CV plot of different electrodes modified with different weight proportions of $\mathrm{CDs} / \mathrm{GO}$ were measured in $10 \mathrm{mM}$ PBS buffer $(\mathrm{pH}=7.4)$ containing $10 \mathrm{mM}$ $\left[\mathrm{Fe}(\mathrm{CN})_{6}\right]^{4-/ 3-}$ and $0.1 \mathrm{M} \mathrm{KCl}$ and shown in Figure $4 \mathrm{~A}$. The peak current responses of $\left[\mathrm{Fe}(\mathrm{CN})_{6}\right]^{4-/ 3-}$ on $\mathrm{CDs} / \mathrm{GO} /$ GCE are considered as indicators to optimize the weight ratio of CDs to GO. It can be seen that the introduction of different weight contents of CDs has a significant effect on the current response for $\mathrm{CDs} / \mathrm{GO} / \mathrm{GCE}$. All $\mathrm{CV}$ curves are characterized by a pair of redox peaks. And $0.32 \mu \mathrm{A}$ of anodic peak current is observed for GO/GCE (curve a). The peak currents increase with the enhancement of the amounts of CDs. The estimated peak current responses corresponding to $\mathrm{CDs} / \mathrm{GO}$ (1:50) and $\mathrm{CDs} / \mathrm{GO}(1: 30)$ are improved to $48.56 \%$ and $157.31 \%$ compared with GO (inset of Figure 4A). When the weight ratio of $\mathrm{CDs}$ is increased to $10 \%(\mathrm{CDs} / \mathrm{GO}$ $(1: 10)), \mathrm{CDs} / \mathrm{GO} / \mathrm{GCE}$ presents a nearly 10 -fold increase in the peak current compared to GO/GCE. Further increase of $\mathrm{CDs}$ weight ratio in $\mathrm{CDs} / \mathrm{GO}$ hybrid leads to a slight increase in peak current for $\left[\mathrm{Fe}(\mathrm{CN})_{6}\right]^{4-/ 3-}$, which are attributed to the excellent electrochemical conductivity of CDs.

Figure 4B shows electrochemical impedance spectroscopy (EIS) for various electrodes coated with all nanocomposites, in which all of the curves are similar and consist of a semicircular part in high-frequency region and a linear part in low-frequency region. The diameter of semicircle, representing electron-transfer resistance $\left(R_{e t}\right)$, gives details about the electron transfer kinetics of $\left[\mathrm{Fe}(\mathrm{CN})_{6}\right]^{4-/ 3-}$ at electrode/ electrolyte interface. It can be seen that GO/GCE (curve a) exhibits the largest $R_{e t}(13,860 \Omega)$, which is due to high resistance and poor conductivity of GO. Initially, the $R_{e t}$ value is slightly decreased as the proportion of CDs increases from (1:50) to (1:30), and sharply drops to 416 $\Omega$ for $\mathrm{CDs} / \mathrm{GO}$ nanocomposites (1:10), then tends to a plateau with further increase in the $\mathrm{CDs} / \mathrm{GO}$ compositional proportion. The results are consistent with the terminology of electrochemistry shown in Figure 4A. Based on the above results, it can be concluded that the incorporation of CDs to $\mathrm{GO}$ matrix enhances the electroconductivity of $\mathrm{CDs} / \mathrm{GO}$ modified GCE. Meanwhile, relatively low weight ratio of $\mathrm{GO}$ in $\mathrm{CDs} / \mathrm{GO}$ nanocomposites would lower the available surface area and the number of anchoring sites which is disadvantage for the immobilization of DNA molecules. To consider a compromise for two factors, the nanocomposites of CDs/GO (1:10) is chosen as the modification material of the electrode for sequence experiments.

\section{Electrochemical Behavior of Different Carbon Nanomaterials Modified Electrodes by Using MB as Indicator}

Methylene blue (MB), as a common electrochemical indicator with a positively charged aromatic structure, has strong affinity to the free guanine bases on DNA molecules. Besides, the duplex protected the guanine moiety from being attacked by MB, leading to the different binding amount of $\mathrm{MB}$ between $\mathrm{MB}$ and single-strand DNA (ssDNA) or double-strand DNA (dsDNA) at the electrode. Therefore, MB often uses as the discriminative reagent toward ssDNA and dsDNA. ${ }^{46}$ Figure 5 illustrates that the DPV responses of the ssDNA/GO/GCE, ssDNA/CDs/GCE
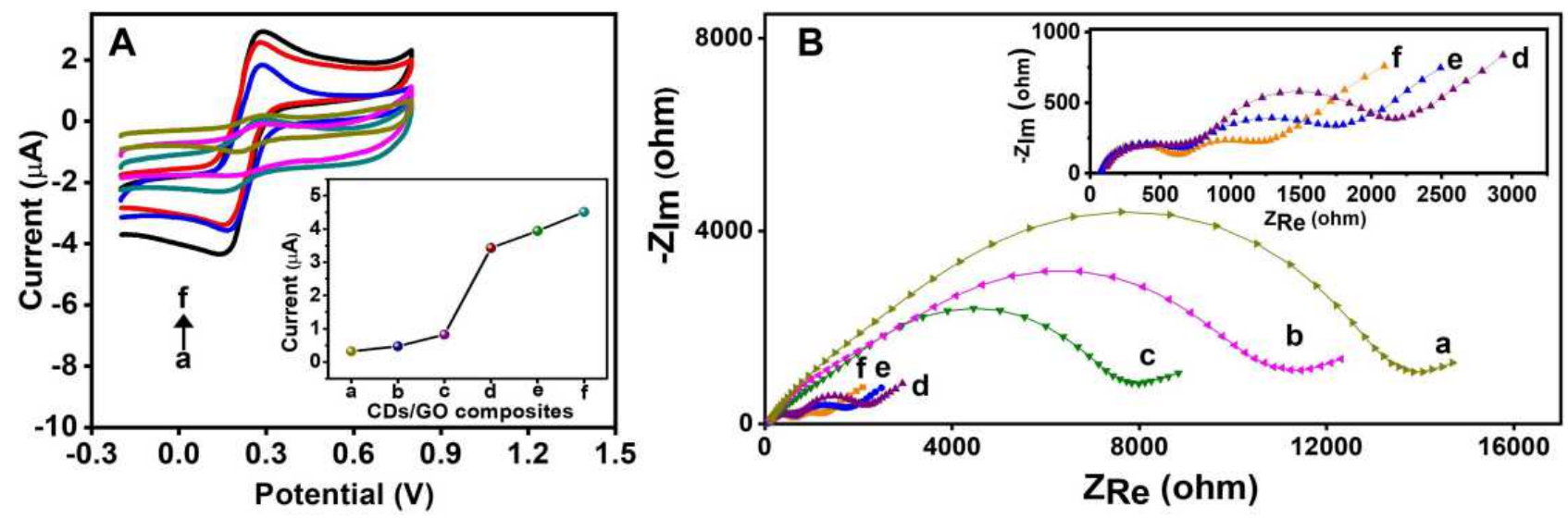

Figure $4 \mathrm{CV}(\mathbf{A})$ and EIS (B) of CDs/GO nanocomposites modified GCE with different weight ratio of CDs to GO, including GO (a), I:50 (b), I:30 (c), I:I0 (d), I:5 (e), I:3 (f). Inset of Figure 4A: anodic peak current with different weight ratio of CDs/GO nanocomposites modified GCE. Inset of Figure 4B: the enlarged ElS of curve $d$, e and $\mathrm{f}$. The above-mentioned electrochemical characteristics of the modified electrodes measured in PBS $(10 \mathrm{mM}, \mathrm{pH} 7.4) \mathrm{containing} 10 \mathrm{mM}\left[\mathrm{Fe}(\mathrm{CN})_{6}\right]^{3,14-}$ and $0.1 \mathrm{M} \mathrm{KCl}$. 


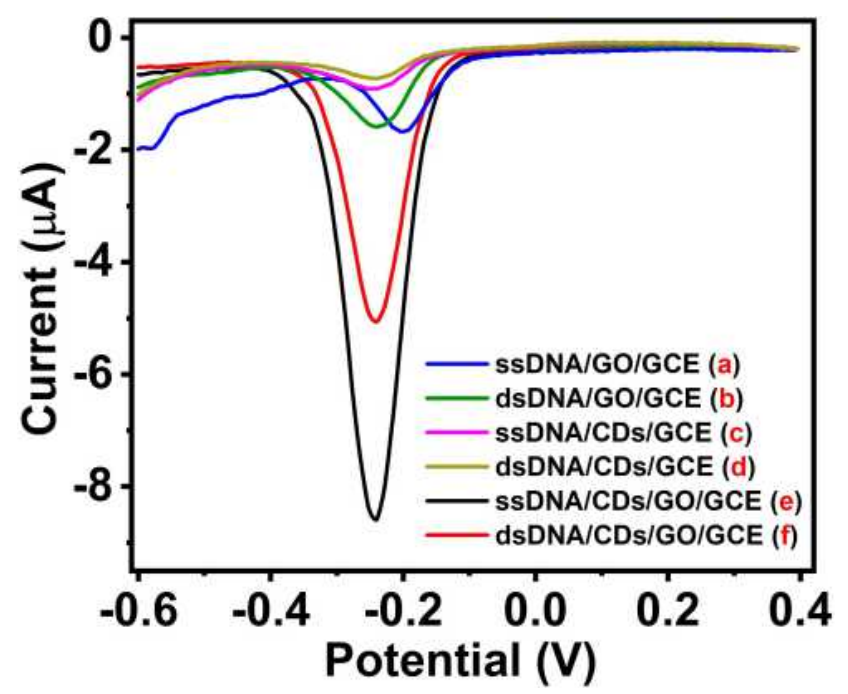

Figure 5 DPV curve of the different materials modified electrodes in a solution of 10 mM PBS (pH 7.4) containing I mM MB: ssDNA/GO/GCE (a), dsDNA/GO/GCE (b), ssDNA/CDs/GCE (c), dsDNA/CDs/GCE (d), ssDNA/CDs/GO/GCE (e) and dsDNA/CDs/GO/GCE (f).

and ssDNA/CDs/GO/GCE accumulated with $1 \mathrm{mM} \mathrm{MB}$ in $10 \mathrm{mM}$ PBS (pH 7.4) after hybridization with complementary target DNA. Upon the incubation with complementary oligonucleotide sequence, the value of peak current responses of the dsDNA/GO/GCE (curve b), dsDNA/ CDs/GCE (curve d) and dsDNA/CDs/GO/GCE (curve f) decreases, respectively, compared with the current signal of the ssDNA/GO/GCE (curve a), ssDNA/CDs/GCE (curve c) and ssDNA/CDs/GO/GCE (curve e), which is due to the inaccessibility of free guanine bases, indicating the hybridization event has occurred. The difference of peak current of the $\mathrm{CDs} / \mathrm{GO} / \mathrm{GCE}, \mathrm{GO} / \mathrm{GCE}$ and $\mathrm{CDs} /$ GCE modified with ssDNA and dsDNA were, respectively, $3.61 \mu \mathrm{A}, 0.25 \mu \mathrm{A}$ and $0.18 \mu \mathrm{A}$. The structure of $\mathrm{CDs} / \mathrm{GO}$ nanocomposites can provide good conductivity of CDs and large planar surface of GO, which would promote electron transfer within the network and enhance hybridization efficiency of DNA. Owing to the aforementioned factors, the current difference $(3.61 \mu \mathrm{A})$ of $\mathrm{MB}$ on $\mathrm{CDs} /$ $\mathrm{GO} / \mathrm{GCE}$ is observably increased by 11 -fold and 20 -fold compared to that on $\mathrm{CDs} / \mathrm{GCE}$ and $\mathrm{GO} / \mathrm{GCE}$, respectively. This dramatic difference of the peak currents between ssDNA/CDs/GO/GCE (curve e) and dsDNA/CDs/GO/ GCE (curve f) by using MB as an electrochemical hybridization indicator suggest that the excellent synergetic effect of $\mathrm{CDs} / \mathrm{GO}$ nanocomposites. These results indicate that the $\mathrm{CDs} / \mathrm{GO}$ nanocomposites not only promote the hybridization of DNA on the electrode surface and enhance the difference of current signals, but also improve the performance of biosensors.

\section{Electrochemical Studies of CDs/GO Modified GCE Biosensor Preparing Process}

In order to characterize the preparing process of the electrochemical biosensor, different stages of CDs/GO (1:10) modified GCE biosensor were tested by ESI in a solution of $0.1 \mathrm{M} \mathrm{KCl}$ containing $10 \mathrm{mM}\left[\mathrm{Fe}(\mathrm{CN})_{6}\right]^{3-/ 4-}$. In this study, $\left[\mathrm{Fe}(\mathrm{CN})_{6}\right]^{3-/ 4-}$ was used as the redox probe, and the semicircle diameter could represent electron transfer resistance $\left(R_{e t}\right)$. Figure $\mathrm{S} 1$ shows the Nyquist plots of impedance spectra at different stages of electrochemical biosensor. The ESI curve of the bare GCE (curve a) exhibits a straight line with subtle bending at higher frequency region. It is well known that GO sheet possesses many oxygen functional groups on its basal planes and edges, including hydroxyl (-OH), epoxy (-O-), carbonyl $(-\mathrm{C}=\mathrm{O})$, and carboxyl groups $(-\mathrm{COOH})$. Among those oxygen functional groups, the $-\mathrm{COO}^{-}$on the surface of the nanocomposite material would develop an electrostatic repulsive force to $\left[\mathrm{Fe}(\mathrm{CN})_{6}\right]^{3-/ 4-}$ anion. In the case of CDs/ $\mathrm{GO} / \mathrm{GCE}$, the value of $R_{e t}$ increases to $2057 \Omega$ (curve b), indicating that the $\mathrm{CDs} / \mathrm{GO}$ nanocomposites blocks the electron transfer on the surface partly because the abundant negative charges carboxyl group on its surface. After amine-labeled single-strand capture DNA with negative charges on its phosphate backbone was fixed to the CDs/ GO surface via amido linkage, the $R_{e t}$ further rises to 3149 $\Omega$ (curve c). The Ret greatly increased when the ssDNA probe was immobilized because the negatively charged phosphate backbone of DNA immobilized on the GCE repelled the $\left[\mathrm{Fe}(\mathrm{CN})_{6}\right] .^{3-/ 4-}$ After hybridization with the target DNA, the value of $R_{e t}$ climbs to $3982 \Omega$ (curve d), because of the large amount of negatively charged DNA linked on the modified electrode. Therefore, these results collectively indicate that the different interfaces of the sensor obtained during the whole preparation process are successfully constructed and that the hybridization of DNA could occur on the surface of electrodes.

\section{Optimization of Conditions for Biosensor}

In order to improve the sensitivity of the biosensor, this work investigates the relevant experimental parameters, including the MB accumulation time, DNA hybridization temperature and hybridization time. Figure $6 \mathrm{~A}$ shows that 

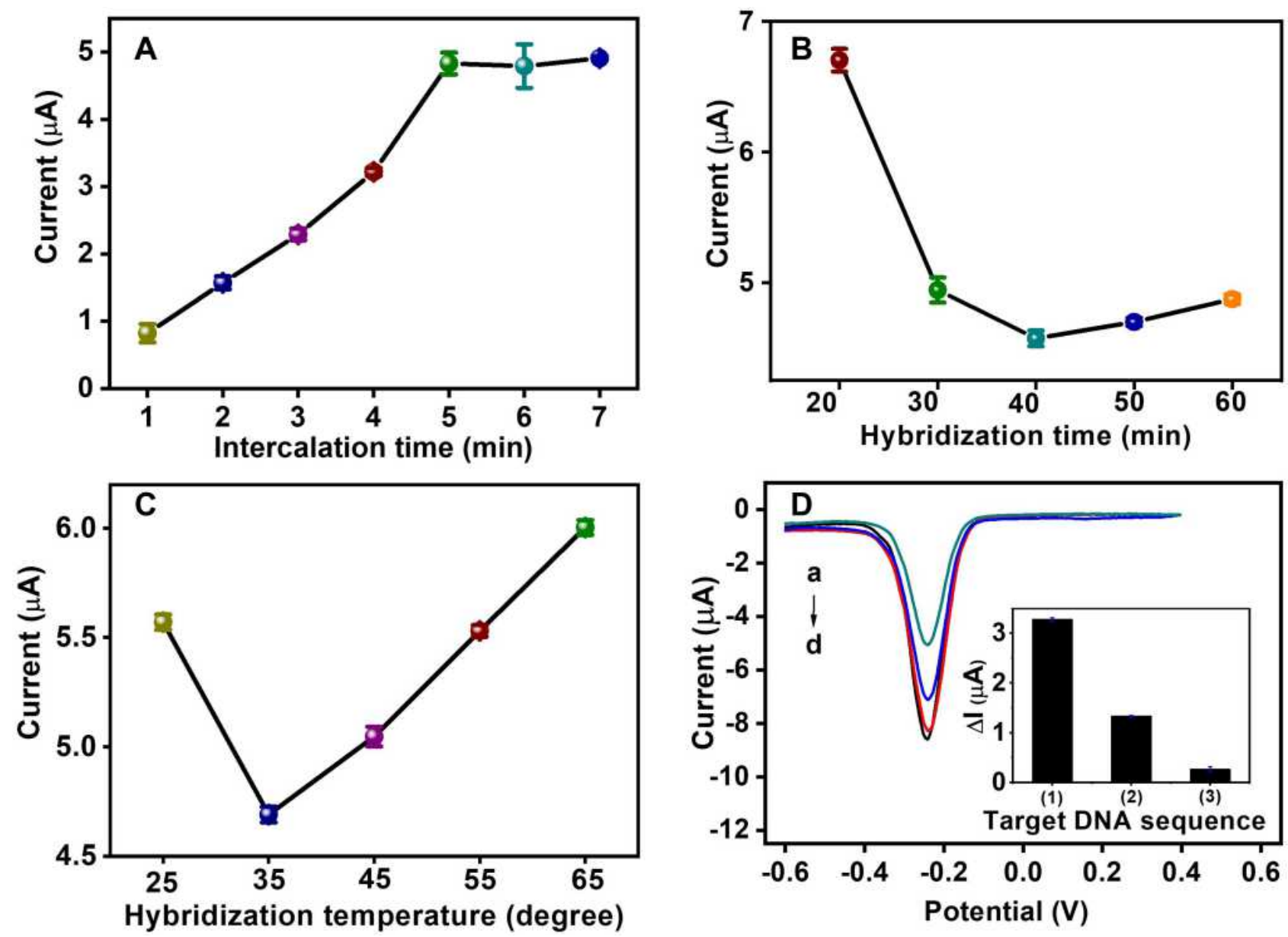

Figure 6 Optimization of experimental conditions: MB accumulation time (A), DNA hybridization time (B) and hybridization temperature (C). Specificity of the biosensor different target DNA (D): complementation target DNA (a); single-mismatched target DNA (b); mismatched target DNA (c); blank (d). Insert in Figure 6D: the difference of current signals $(\Delta \mathrm{I})$ of complementary target DNA (I), one base-mismatch target DNA (2) and non-complementary target DNA (3). $\Delta \mathrm{I}=\mathrm{I}-\mathrm{I}$ blank.

the current signal increased with the $\mathrm{MB}$ accumulation time increasing when the time is below $5 \mathrm{~min}$. But, further increase of the $\mathrm{MB}$ accumulation time from 5 to $7 \mathrm{~V}$, the peak current was constant. Therefore, 5 min was selected as the optimal $\mathrm{MB}$ accumulation time.

As we all know, the hybridization time and hybridization temperature act as very important parameters in the hybridization process. A series of experiments were performed to optimize these parameters. The peak current decreased with hybridization time from 20 to $40 \mathrm{~min}$ and reached minimum current at $40 \mathrm{~min}$ (Figure 6B). Beyond this hybridization time, the $\mathrm{MB}$ single almost reached constant. This result indicates that the hybridization reaction was complete after $40 \mathrm{~min}$. Besides, as shown in Figure $6 \mathrm{C}$, the hybridization temperature was investigated by DPV in the range from 25 to $65^{\circ} \mathrm{C}$. The peak current decreased significantly with the increase of the hybridization temperature to $35^{\circ} \mathrm{C}$. However, the peak current increased with further increased hybridization temperature from 35 to $65^{\circ} \mathrm{C}$. To deduce the reason for current signal decrease, the overheating environment accelerates the denaturation of dsDNA, resulting in the decrease of the hybridization number, which would hinder the hybridization efficiency and decrease the electron transfer on electrode surface. Thus, the optimal hybridization time and hybridization temperature were set at $40 \mathrm{~min}$ and $35^{\circ} \mathrm{C}$ respectively.

\section{Specificity of Biosensor}

In order to verify the specificity of electrochemical biosensor, the DNA biosensor was examined using capture probe DNA for hybridization with several different target DNA sequences under the optimal conditions. The Figure $6 \mathrm{D}$ illustrates that the current signal of capture probe DNA/CDs/GO/GCE (curve d), complementary target DNA (curve a), one base-mismatch target DNA (curve b) 
and non-complementary target DNA (curve c). The peak current of complementary target DNA (curve a) is obviously lower than other base-mismatch sequence (curve b and curve c) under the optimal experimental conditions. The difference of current signal $(\Delta \mathrm{I})$ was obtained the current signal of the biosensor after hybridization with different mismatched target DNA (curve $a, b$, c) compared with the current signal of capture probe DNA/CDs/GO/GCE (curve d), which is presented as histogram in the inset in Figure $6 \mathrm{D}(\Delta \mathrm{I}=\mathrm{I}-\mathrm{I}$ blank, I: the current signal of the capture probe DNA/CDs/GO/GCE after hybridization with different mismatched target DNA, I blank: the current signal of capture probe DNA/ $\mathrm{CDs} / \mathrm{GO} / \mathrm{GCE})$. The $\Delta \mathrm{I}$ of the biosensor after hybridization with complementary target DNA (1), one basemismatch target DNA (2) and non-complementary target DNA (3) were, respectively, $3.28 \mu \mathrm{A}, 1.33 \mu \mathrm{A}$ and 0.26 $\mu \mathrm{A}$. The $\Delta \mathrm{I}$ of one-base mismatch and non-complementary DNA were $41 \%$ and $8 \%$ that of complementary target DNA, respectively, indicating that the developed DNA biosensor possessed excellent specificity.

Simultaneously, the stability and reproducibility of the biosensor was investigated, which could be found in the section of "Stability and reproducibility of the biosensorSupplementary Information."

\section{Analytical Performance of Biosensor}

Under the optimal experimental conditions, different concentrations of complementary target DNA in PBS
(10 mM, pH 7.4) were detected by DPV in order to detect the linear relationship of the electrochemical DNA biosensor based on the CDs/GO nanocomposites modified GCE. Besides, the linear relationship was studied between different concentration of DNA target sequence and $\Delta \mathrm{I}$. The results are displayed in Figure 7, the $\Delta \mathrm{I}$ increased accordingly with the increase of the complementary target DNA concentration from $1.00 \times 10^{-11} \mathrm{M}$ to $2.25 \times 10^{-9}$ M. Moreover, when the concentration is greater than $2.25 \times 10^{-9} \mathrm{M}$, the peak current intensity is almost stable (Figure 7A), indicating that the probe fixed on the electrode surface has been hybridized completely. Besides, as shown in Figure $7 \mathrm{~B}$, the $\Delta \mathrm{I}$ has a good linear relationship with the different concentrations of target DNA from $2.50 \times 10^{-10} \mathrm{M}$ to $2.25 \times 10^{-9} \mathrm{M}$. The regression equation was expressed as $\lg \Delta \mathrm{I}=0.04672+1.113 \mathrm{C}(\mathrm{C}$ is the concentration of target DNA in the solution) and a good linear correlation coefficient of 0.9885 (Inset in Figure $6 \mathrm{~B})$. The detection limit was $8.30 \times 10^{-11} \mathrm{M}$ based on the ratio of signal-to-noise of 3 .

Those results showed that the electrochemical biosensor based on $\mathrm{CDs} / \mathrm{GO}$ modified GCE with relatively high sensibility, which was attributed to the abundant carboxyl group on GO surface to increasing of combination with the capture DNA and the improved conductivity caused by $\mathrm{CDs}$ in the nanocomposite material. While the detection range is not very wide, the DNA biosensor would provide a good basis of further detection research in practical samples.
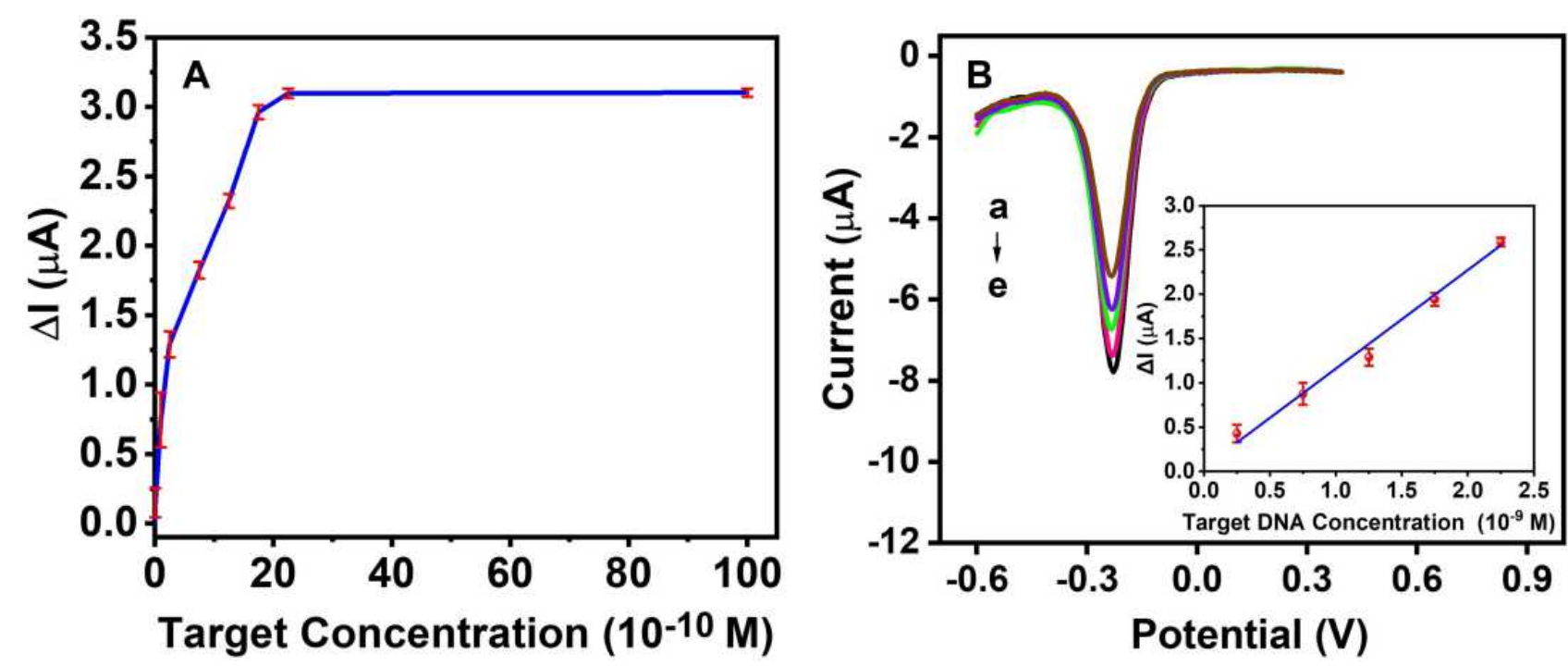

Figure 7 (A) The linear relationship between the different concentration of DNA target and $\triangle \mathrm{I}$. (B) DPV curves after hybridization with different target concentration $\left(\times 10^{-9} \mathrm{M}\right.$ : (a) 2.25, (b) 1.75, (c) 1.25, (d) 0.75, (e) 0.25. Insert in Figure 7B shows that the linear relationship between the logarithmic of different concentration of DNA target and $\Delta \mathrm{l}$. 


\section{Conclusion}

In summary, a novel electrochemical DNA biosensor platform was fabricated for the detection of PML/ RAR $\alpha$ fusion gene. Moreover, this biosensor was based on $\mathrm{CDs} / \mathrm{GO}$ nanocomposites modified $\mathrm{GCE}$ interface, and $\mathrm{MB}$ as an electrochemical indicator. Besides, the $\mathrm{CDs} / \mathrm{GO}$ nanocomposites were prepared by the facile exsitu synthetic method, and this method had the advantages of simplicity, low cost and environmental. Under optimal condition, owing to the large specific area and good conductivity of the $\mathrm{CDs} / \mathrm{GO}$ nanocomposites, the nanocomposites modified DNA biosensor offers appealing advantages, such as higher sensitivity, lower detection limit and better reproducibility as compared to pure $\mathrm{CDs}$ and GO modified. Furthermore, the excellent specificity of the new electrochemical DNA biosensor for the detection of target DNA sequence has been demonstrated. Therefore, the work has application potential in clinical diagnostic testing for APL or other genetic diseases, and promote the development of other rapid, economical and convenient electrochemical biosensors.

\section{Acknowledgements}

The authors gratefully acknowledge the financial support of the Natural Science Foundation of China (21775023). Joint Funds for the Innovation of Science and Technology, Fujian Province (2019Y9005) and the Natural Science Foundation of Fujian Province of China (2019J01301).

\section{Disclosure}

The authors report no conflict of interests in this work.

\section{References}

1. Grimwade D, Ivey A, Huntly BJP. Molecular landscape of acute myeloid leukemia in younger adults and its clinical relevance. Blood. 2016;127(1):29-41. doi:10.1182/blood-2015-07-604496

2. Zhao J, Liang JW, Xue HL, et al. The genetics and clinical characteristics of children morphologically diagnosed as acute promyelocytic leukemia. Leukemia. 2019;33(6):1387-1399. doi:10.1038/s41375-018-0338-z

3. Sanz MA, Fenaux P, Tallman MS, et al. Management of acute promyelocytic leukemia: updated recommendations from an expert panel of the European LeukemiaNet. Blood. 2019;133(15):1630-1643. doi:10.1182/blood-2019-01-894980

4. Chen XY, Wood BL. Monitoring minimal residual disease in acute leukemia: technical challenges and interpretive complexities. Blood Rev. 2017;31(2):63-75. doi:10.1016/j.blre.2016.09.006

5. Grimwade LF, Fuller KA, Erber WN. Applications of imaging flow cytometry in the diagnostic assessment of acute leukaemia. Methods. 2019;112:39-45. doi:10.1016/j.ymeth.2016.06.023

6. Osumi T, Tsujimoto S, Tamura M, et al. Recurrent RARB translocations in acute promyelocytic leukemia lacking RARA translocation. Cancer Res. 2018;78(16):4452-4458. doi:10.1158/0008-5472.CAN-18-0840
7. Arvand M, Sanayeei M, Hemmati S. Label-free electrochemical DNA biosensor for guanine and adenine by ds-DNA/poly (L-cysteine)/Fe3O4 nanoparticles-graphene oxide nanocomposite modified electrode. Biosens Bioelectron. 2018;102:70-79. doi:10.1016/j.bios.2017.11.002

8. Zheng Y, Wang XY, He SQ, et al. Aptamer-DNA concatamer-quantum dots based electrochemical biosensing strategy for green and ultrasensitive detection of tumor cells via mercury-free anodic stripping voltammetry. Biosens Bioelectron. 2019;126: 261-268. doi:10.1016/j.bios.2018.09.076

9. Maghsoudi AS, Hassani S, Mirnia K, et al. Recent advances in nanotechnology-based biosensors development for detection of arsenic, lead, mercury, and cadmium. Int J Nanomed. 2021;16: 803-832. doi:10.2147/IJN.S294417

10. Srisomwat C, Yakoh A, Chuaypen N, et al. Amplification-free DNA sensor for the one-step detection of the Hepatitis B virus using an automated paper-based lateral flow electrochemical device. Anal Chem. 2021;93(5):2879-2887. doi:10.1021/acs.analchem.0c04283

11. Nguyet NT, Yen LTH, Doan VY, et al. A label-free and highly sensitive DNA biosensor based on the core-shell structured CeO2-NR@Ppy nanocomposite for Salmonella detection. Mater Sci Eng C. 2019;96:790-797. doi:10.1016/j.msec.2018.11.059

12. Su S, Cao WF, Liu W, et al. Dual-mode electrochemical analysis of microRNA-21 using gold nanoparticle-decorated MoS2 nanosheet. Biosens Bioelectron. 2017;94:552-559. doi:10.1016/j.bios.2017.03.040

13. Divya KP, Karthikeyan R, Sinduja B, et al. Carbon dots stabilized silver-lipid nano hybrids for sensitive label free DNA detection. Biosens Bioelectron. 2019;133:48-54. doi:10.1016/j.bios.2019.03. 027

14. Huang JY, Zhao L, Lei W, et al. A high-sensitivity electrochemical aptasensor of carcinoembryonic antigen based on graphene quantum dots-ionic liquid-nafion nanomatrix and DNAzyme-assisted signal amplification strategy. Biosens Bioelectron. 2018;99:28-33. doi:10.1016/j.bios.2017.07.036

15. Moulick A, Milosavljevic V, Vlachova J, et al. Using CdTe/ZnSe core/shell quantum dots to detect DNA and damage to DNA. Int J Nanomed. 2017;12:1277-1291. doi:10.2147/IJN.S121840

16. Chen M, Hou CJ, Huo DQ, Fa HB, Zhao YN, Shen CH. A sensitive electrochemical DNA biosensor based on three-dimensional nitrogen-doped graphene and Fe3O4 nanoparticles. Sens Actuator B-Chem. 2017;239:421-429. doi:10.1016/j.snb.2016.08.036

17. Miao P, Tang YG, Wang L. DNA modified Fe3O4@Au magnetic nanoparticles as selective probes for simultaneous detection of heavy metal ions. ACS Appl Mater Interfaces. 2017;9(4):3940-3947. doi:10.1021/acsami.6b14247

18. Zhang W, Dai ZC, Liu X, et al. High-performance electrochemical sensing of circulating tumor DNA in peripheral blood based on poly-xanthurenic acid functionalized MoS2 nanosheets. Biosens Bioelectron. 2018;105:116-120. doi:10.1016/j.bios.2018.01.038

19. Wongkaew N, Simsek M, Griesche C, Baeumner AJ. Functional nanomaterials and nanostructures enhancing electrochemical biosensors and lab-on-a-chip performances: recent progress, applications, and future perspective. Chem Rev. 2019;119(1):120-194. doi:10.1021/acs.chemrev.8b00172

20. Torres D, Perez-Rodriguez S, Sebastian D, Pinilla JL, Lazaro MJ, Suelves I. Graphene oxide nanofibers: a nanocarbon material with tuneable electrochemical properties. Appl Surf Sci. 2020;509:144774. doi:10.1016/j.apsusc.2019.144774

21. Georgakilas V, Tiwari JN, Kemp KC, et al. Noncovalent functionalization of graphene and graphene oxide for energy materials, biosensing, catalytic, and biomedical applications. Chem Rev. 2016;116 (9):5464-5519. doi:10.1021/acs.chemrev.5b00620

22. Fauzi ASA, Hamidah NL, Sato S, et al. Carbon-based potentiometric hydrogen sensor using a proton conducting graphene oxide membrane coupled with a WO3 sensing electrode. Sens Actuator B Chem. 2020;323:128678. doi:10.1016/j.snb.2020.128678 
23. Lee J, Kim J, Kim S, Min DH. Biosensors based on graphene oxide and its biomedical application. Adv Drug Deliv Rev. 2016;105:275-287. doi:10.1016/j.addr.2016.06.001

24. Jume BH, Gabris MA, Nodeh HR, Rezania S, Cho J. Biodiesel production from waste cooking oil using a novel heterogeneous catalyst based on graphene oxide doped metal oxide nanoparticles. Renew Energy. 2020;162:2182-2189. doi:10.1016/j.renene.2020.10. 046

25. Zhu JM, Ye ZL, Fan XY, et al. A highly sensitive biosensor based on $\mathrm{Au} \mathrm{NPs} / \mathrm{rGO}-\mathrm{PAMAM}-\mathrm{Fc}$ nanomaterials for detection of cholesterol. Int J Nanomed. 2019;14:835-849. doi:10.2147/IJN.S184013

26. Fan Q, Li JH, Wang JY, et al. Ultrasensitive $\mathrm{Fe}^{3+}$ ion detection based on carbon quantum dot-functionalized solution-gated graphene transistors. J Mater Chem C. 2020;8(14):4685-4689. doi:10.1039/ d0tc00635a

27. Rasheed PA, Sandhyarani N. Carbon nanostructures as immobilization platform for DNA: a review on current progress in electrochemical DNA sensors. Biosens Bioelectron. 2017;97:226-237. doi:10.1016/j.bios.2017.06.001

28. Baig N, Sajid M, Saleh TA. Recent trends in nanomaterial-modified electrodes for electroanalytical applications. Trends Analyt Chem. 2019;111:47-61. doi:10.1016/j.trac.2018.11.044

29. Khodadadi A, Faghih-Mirzaei E, Karimi-Maleh H, et al. A new epirubicin biosensor based on amplifying DNA interactions with polypyrrole and nitrogen-doped reduced graphene: experimental and docking theoretical investigations. Sens Actuator B Chem. 2019;284:568-574. doi:10.1016/j.snb.2018.12.164

30. Xia CL, Zhu SJ, Feng TL, Yang MX, Yang B. Evolution and synthesis of carbon dots: from carbon dots to carbonized polymer dots. Adv Sci. 2019;6(23):1901316. doi:10.1002/advs.201901316

31. Lima CS, Hola K, Ambrosi A, Zboril R, Pumera M. Graphene and carbon quantum dots electrochemistry. Electrochem Commun. 2015;52:75-79. doi:10.1016/j.elecom.2015.01.023

32. Zhong X, Li X, Ying Z, Chai YQ, Yuan R. Synthesizing anode electrochemiluminescent self-catalyzed carbon dots-based nanocomposites and its application in sensitive ECL biosensor for microRNA detection. Sens Actuator B Chem. 2020;305:127490. doi:10.1016/j. snb.2019.127490

33. Hoang VC, Dave K, Gomes VG. Carbon quantum dot-based composites for energy storage and electrocatalysis: mechanism, applications and future prospects. Nano Energy. 2019;66:104093. doi:10.1016/j. nanoen.2019.104093

34. Algarra M, Gonzalez-Calabuig A, Radotic K, et al. Enhanced electrochemical response of carbon quantum dot modified electrodes, applications and future prospects. Talanta. 2018;178:679-685. doi:10.1016/j.talanta.2017.09.082

35. Cai ZT, Ye YB, Wan X, et al. Morphology-dependent electrochemical sensing properties of iron oxide-graphene oxide nanohybrids for dopamine and uric acid. Nanomaterials. 2019;9(6):835. doi:10.33 90/nano9060835
36. Li RY, Zhu HY, Li ZJ, Liu JK. Electrochemical determination of acetaminophen using a glassy carbon electrode modified with a hybrid material consisting of graphene aerogel and octadecylamine-functionalized carbon quantum dots. Microchim Acta. 2018;185(2):145. doi:10.1007/s00604-018-2688-7

37. Yang LQ, Huang N, Lu QJ, et al. A quadruplet electrochemical platform for ultrasensitive and simultaneous detection of ascorbic acid, dopamine, uric acid and acetaminophen based on a ferrocene derivative functional $\mathrm{Au} \mathrm{NPs/carbon} \mathrm{dots} \mathrm{nanocomposite} \mathrm{and} \mathrm{gra-}$ phene. Anal Chim Acta. 2015;903:69-80. doi:10.1016/j. aca.2015.11.021

38. Chen DD, Zhuang XM, Zhai J, Zheng YY, Lua H, Chen LX. Preparation of highly sensitive Pt nanoparticles-carbon quantum dots/ionic liquid functionalized graphene oxide nanocomposites and application for $\mathrm{H} 2 \mathrm{O} 2$ detection. Sens Actuator B-Chem. 2018;255:1500-1506. doi:10.1016/j.snb.2017.08.156

39. Canevari TC, Rossi MV, Alexiou ADP. Development of an electrochemical sensor of endocrine disruptor bisphenol A by reduced graphene oxide for incorporation of spherical carbon nanoparticles. $J \quad$ Electroanal Chem. 2019;832:24-30. doi:10.1016/j. jelechem.2018.10.0441

40. Li LB, Liu D, Shi AP, You TY. Simultaneous stripping determination of cadmium and lead ions based on the N-doped carbon quantum dots-graphene oxide hybrid. Sens Actuator B-Chem. 2018;255:17621770. doi:10.1016/j.snb.2017.08.1901

41. Huang QT, Lin XF, Zhu JJ, Tong QX. Pd-Au@carbon dots nanocomposite: facile synthesis and application as an ultrasensitive electrochemical biosensor for determination of colitoxin DNA in human serum. Biosens Bioelectron. 2017;94:507-512. doi:10.1016/j. bios.2017.03.048

42. Jamaluddin RZAR, Tan LL, Chong KF, Heng LY. An electrochemical DNA biosensor fabricated from graphene decorated with graphitic nanospheres. Nanotechnology. 2020;31(48):85501. doi:10.1088/ 1361-6528/abab2e

43. Rafiee-Pour HA, Behpour M, Keshavarz M. A novel label-free electrochemical miRNA biosensor using methylene blue as redox indicator: application to breast cancer biomarker miRNA-21. Biosens Bioelectron. 2016;77:202-207. doi:10.1016/j.bios.2015.09.025

44. Sani NDM, Ariffin EY, Sheryn W, et al. An electrochemical DNA biosensor for carcinogenicity of anticancer compounds based on competition between methylene blue and oligonucleotides. Sensors. 2019;19(23):5111. doi:10.3390/s19235111

45. Liu C, Bao L, Tang B, et al. Fluorescence-converging carbon nanodots-hybridized silica nanosphere. Small. 2016;12(34):47 02-4706. doi:10.1002/smll.201503958

46. Lin KC, Yin CY, Chen SM. An electrochemical biosensor for determination of hydrogen peroxide using nanocomposite of poly (methylene blue) and FAD hybrid film. Sens Actuator B Chem. 2011;157 (1):202-210. doi:10.1016/j.snb.2011.03.050
International Journal of Nanomedicine

\section{Publish your work in this journal}

The International Journal of Nanomedicine is an international, peerreviewed journal focusing on the application of nanotechnology in diagnostics, therapeutics, and drug delivery systems throughout the biomedical field. This journal is indexed on PubMed Central, MedLine, CAS, SciSearch ${ }^{\mathbb{R}}$, Current Contents ${ }^{\mathbb{R}} /$ Clinical Medicine, $^{2}$
Journal Citation Reports/Science Edition, EMBase, Scopus and the Elsevier Bibliographic databases. The manuscript management system is completely online and includes a very quick and fair peer-review system, which is all easy to use. Visit http://www.dovepress.com/ testimonials.php to read real quotes from published authors. 